\title{
A FORMAÇÃO CONTINUADA DE PROFESSORES ALFABETIZADORES NO MUNICÍPIO DE SÃO BORJA-RS: UM ESTUDO SOBRE O PNAIC - MATEMÁTICA
}

\author{
THE CONTINUED EDUCATION OF LITERACY TEACHERS IN \\ THE CITY OF SÃO BORJA-RS: A STUDY ON THE PNAIC - MATHEMATICS \\ ANA PAULA UFLACKER TOJA* \\ RICARDO FAJARDO**
}

\section{RESUMO}

Este artigo é um recorte de uma dissertação de mestrado do Programa de Pós-Graduação em Educação Matemática e Ensino de Física da Universidade Federal de Santa Maria (UFSM). A pesquisa investigou as contribuições do programa Pacto Nacional pela Alfabetização na Idade Certa (PNAIC) para a formação continuada de professores alfabetizadores do município de São Borja/RS, em especial, o PNAIC-Matemática. Participaram da pesquisa 24 professoras de 13 escolas da rede municipal de ensino da cidade de São Borja. A teoria foi embasada em obras de autores como: Imbernón, Garcia, Nóvoa, entre outros. Para a coleta de dados foi utilizado um questionário misto, interpretados por meio da análise de conteúdo de Bardin. Por meio da análise dos dados obtidos na pesquisa evidenciou-se que as ações desenvolvidas no âmbito do PNAIC proporcionaram algumas reflexões em torno da atuação das professoras em sala de aula, promovendo o repensar da própria prática pedagógica.

Palavras-chave: PNAIC. Formação continuada de professores. Alfabetização Matemática. Professores Alfabetizadores.

\section{ABSTRACT}

This article is a cross-section of a master's thesis presented to the Graduate Program in Mathematical Education and Teaching of Physics of the Federal University of Santa Maria (UFSM). The research investigated the contributions of the National Pact for Literacy in the Right Age (PNAIC) program for the continuing education of literacy teachers in the municipality of São Borja / RS, especially the PNAIC-Mathematics. Twenty-four teachers from 13 schools of the municipal school system of the city of São Borja participated in the research. The theory was based on works by authors such as: Imbernón, Garcia, Nóvoa, among others. For data collection a mixed questionnaire was used, which were interpreted through Bardin content analysis. Through the analysis of the data obtained in the research, it was shown that the actions developed within the framework of the PNAIC provided some reflections about the teachers' performance in the classroom, promoting a rethinking of the pedagogical practice itself.

Keywords: PNAIC.; Continuing education of teacher. literacy Mathematics. Teachers Literacy.

\footnotetext{
* Mestre em Educação Matemática. E-mail: anapaulatoja@hotmail.com. Orcid: https://orcid.org/0000-0001-5698-6858.

** Doutor em Matemática, Coordenador do Programa de Pós-Graduação em Educação Matemática e Ensino de Física (PPGEMEF) do Centro de Ciências Naturais e Exatas (CCNE) da Universidade Federal de Santa Maria (UFSM), Santa Maria, RS, Brasil. E-mail: rfaj@ufsm.br. Orcid: https://orcid.org/0000-0002-9416-713X.
} 


\section{INTRODUÇÃO}

Este artigo ${ }^{1}$ é um recorte de uma dissertação $0^{2}$ de mestrado apresentada ao Programa de Pós- Graduação em Educação Matemática e Ensino de Física da Universidade Federal de Santa Maria (UFSM). A pesquisa investigou as contribuições do programa Pacto Nacional de Alfabetização na Idade Certa (PNAIC) para a formação continuada de professores alfabetizadores do município de São Borja, que aconteceu no ano de 2014, em que o foco foi a Alfabetização Matemática.

Para melhorar a formação dos professores dos anos iniciais do Ensino Fundamental, a partir do ano de 2013, o governo federal passou a oferecer formações continuadas em nível nacional aos professores alfabetizadores atuantes, por meio do PNAIC. 0 referido programa foi realizado na modalidade presencial, destinado, inicialmente, aos professores que atuavam no primeiro, segundo e terceiro ano do Ensino Fundamental.

No ano de 2013, a ênfase do PNAIC foi a formação em Língua Portuguesa e, em 2014, na formação em Matemática. Em 2015, o programa foi ampliado para as demais áreas do conhecimento, assumindo uma abordagem interdisciplinar. No ano de 2016, a ênfase foi a criança, buscando "a consolidação dos direitos, das competências e das habilidades de Leitura, escrita e Matemática previstos para serem alcançados em cada ano do Ciclo de Alfabetização" (BRASIL, 2017, p. 11). Em 2017, 0 tema do PNAIC foi: ser alfabetizada é direito da criança.

0 PNAIC foi criado em 4 de julho de 2012 por meio da portaria $n^{0} 867$, a qual instituiu as ações do pacto e definiu suas diretrizes gerais. Segundo o documento, os entes governamentais poderiam aderir voluntariamente ao PNAIC e, se assim o fizessem, deveriam concordar com o Termo de Adesão que foi formalizado em instrumento próprio disponibilizado pelo MEC. Ao aderirem, os Estados, Municípios e 0 Distrito Federal assumiram o compromisso de alfabetizar as crianças até, no máximo, os 8 anos de idade, ao final do $3^{\circ}$ ano do Ensino Fundamental. Além do mais, deveriam garantir a alfabetização em Língua Portuguesa e em Matemática. Para acompanhar o desempenho dos estudantes, 0 Instituto Nacional de Estudos e Pesquisas Educacionais Anísio Teixeira (INEP) realizou avaliações anuais universais para os concluintes do $3^{\circ}$ ano do Ensino Fundamental. Os municípios que aderiram ao PNAIC receberam apoio gerencial dos estados para garantir a sua efetiva implantação (BRASIL, 2012).

Segundo 0 Artigo $1^{\circ}$ da referida portaria $n^{0} 867$, o compromisso também abrangeria:

I - a alfabetização em língua portuguesa e em matemática;

II - a realização de avaliações anuais universais, pelo Instituto Nacional de Estudos e Pesquisas Educacionais Anísio Teixeira - INEP, para os concluintes do $3^{0}$ ano do ensino fundamental;

III - 0 apoio gerencial dos estados, aos municípios que tenham aderido às ações do Pacto, para sua efetiva implementação (BRASIL, 2012, p. 01).

Como eixo principal, o PNAIC focou na formação continuada de professores alfabetizadores, 0 qual abrangeu a formação desses profissionais das escolas das redes de ensino participantes, assim como a formação e a constituição de uma rede de professores orientadores de estudo.

Estas formações eram realizadas através de ações que tinham como objetivo apoiar todos os professores atuantes no ciclo de alfabetização a planejarem as aulas e a usarem, de modo articulado,

10 presente trabalho foi realizado com o apoio da Coordenação de Aperfeiçoamento de Pessoal de Nível Superior - Brasil (CAPES) - Código de financiamento 001.

2 As contribuições do PNAIC-Matemática na formação de professores alfabetizadores do município de São Borja. (TOJA, 2018) 
os materiais e as referências curriculares e pedagógicas ofertados pelo MEC às redes que aderiram ao PNAIC. As universidades, secretarias de educação e escolas deveriam se articular para a realização do processo formativo dos professores alfabetizadores atuantes nas escolas (BRASIL, 2013).

0 PNAIC iniciou os cursos de formação de professores em 2013 quando já contava com a adesão da maioria dos municípios, um total de 5.420 em 27 estados e o Distrito Federal. No ano de 2014, aderiram ao PNAIC mais 77 municípios. Ao todo, foram aproximadamente 310 mil professoras alfabetizadoras e mais de 15 mil orientadores de estudo participantes nos anos de 2013 e 2014. Além das formações, um dos eixos do programa previa a distribuição de materiais didáticos, obras literárias, obras de apoio pedagógico, jogos e tecnologias educacionais. Assim, cada turma de alfabetização recebeu materiais didáticos e pedagógicos, tais como livros didáticos, obras complementares aos livros didáticos, acervos de dicionários, jogos pedagógicos, obras de apoio pedagógico, todos destinados à alfabetização. Os professores alfabetizadores receberam um kit de formação constituído de 35 cadernos de Língua Portuguesa e 13 cadernos de Matemática, abordando diferentes conteúdos relacionados à alfabetização na perspectiva do letramento, além de propostas de atividades e sugestões de ampliação do estudo.

Os cursos de formação foram desenvolvidos por Instituições de Ensino Superior (IES) selecionadas pelo MEC, para esse fim. No ano de 2013, participaram do PNAIC 38 IES, sendo 32 Federais e 6 Estaduais. No ano de 2014, ingressaram ao grupo mais 3 IES. No Rio Grande do Sul, os cursos de formação foram realizados sob a responsabilidade de duas Universidades: a Universidade Federal de Santa Maria (UFSM) e a Universidade Federal de Pelotas (UFPel). A equipe responsável por coordenar todas as atividades da formação é foi constituída por profissionais das próprias universidades.

A equipe da UFPel ${ }^{3}$ foi formada por 3 professores coordenadores, 5 supervisores e 32 formadores e foi responsável pela coordenação de 3 polos -1 em Pelotas e 2 em Porto Alegre. Essa equipe foi responsável pela formação de 517 orientadores de estudo e mais de 10.000 professores alfabetizadores, de 150 municípios da região meridional do Rio Grande do Sul, dando continuidade ao trabalho realizado em 2013. Na edição 2012/2013, com foco na área de Alfabetização e Linguagem, a equipe da UFSM ${ }^{4}$ era composta por 20 formadores e 541 professores orientadores de estudo, contemplando a formação de 8.600 professores alfabetizadores da rede pública municipal e estadual do Rio Grande do Sul, em 325 municípios que fizeram adesão ao PNAIC por 42 formadores e 552 professores orientadores de estudo. Contemplou, aproximadamente, a formação de 8.143 professores alfabetizadores da rede pública municipal e estadual do Rio Grande do Sul, com a participação de 324 municípios. No ano de 2015, com 0 início do trabalho interdisciplinar, participaram do programa, aproximadamente, 8.143 professores alfabetizadores, 546 orientadores de estudos e 20 formadores, com a participação de 332 municípios.

Em São Borja, participaram das formações do PNAIC-Matemática, no ano de 2014, 89 professores alfabetizadores das 19 escolas da rede municipal de ensino que, na época, estavam atuando em turmas do $1^{0}$ ao $3^{0}$ ano do Ensino Fundamental. A formação contou com 1 coordenadora e 33 orientadoras de estudos.

Pela legislação vigente, é foi estimulada uma parceria entre as instituições educacionais para realizar as formações. É necessário ressaltar a importância dessa parceria, já que "é inútil propor uma qualificação baseada na investigação e parcerias entre escolas e instituições universitárias se os normativos legais persistirem em dificultar esta aproximação" (NÓVOA, 2009, p. 21). Esta articulação é foi uma oportunidade para que as instituições educacionais envolvidas pudessem refletir acerca da

3 Informação encontrada na página da UFPel destinada a divulgar informações referente ao PNAIC. http://pnaic.ufpel.edu.br/. 4 Informação encontrada na página da UFSM destinada a divulgar informações referente ao PNAIC. http://coral.ufsm.br/ pactonacional/index.php/sobre. 
profissão docente em conjunto, desenvolvendo formações que venham ao encontro das necessidades formativas dos professores.

A formação continuada é uma oportunidade dos professores estarem em constante processo de atualização, frente às inovações tecnológicas que aconteceram nas últimas décadas. É uma oportunidade de construir e aperfeiçoar conhecimentos que Ihes permitam analisar processos de aprendizagem dos alunos, suas dificuldades, propor e refletir sobre situações didáticas, avaliar 0 desempenho dos alunos e a própria prática docente. Candau (2009)

Qualquer possibilidade de êxito do processo que se pretenda mobilizar tem no/a professor/a em exercício seu principal agente. Neste sentido, a formação continuada constitui, sem dúvida, um tema de particular atualidade, de natureza complexa e que pode ser abordado e analisado a partir de diferentes enfoques, dimensões e estratégias (CANDAU, 2009, p. 01).

Portanto, para acompanhar as mudanças sociais, econômicas e tecnológicas das últimas décadas, torna-se necessário investir no professor para atingir uma educação de qualidade. Este deveria estar em constante processo de formação.

A formação de professores é um processo de desenvolvimento pessoal que tem como objetivo adquirir ou aperfeiçoar habilidades em sujeitos encarregados de educar as novas gerações, por meio da interação entre formador e formando desenvolvida num contexto organizado e institucional mais ou menos delimitado (GARCIA, 1999). 0 professor precisa estar preparado para ensinar. Por isso, ele necessita de uma formação que o torne capacitado para o desempenho de suas atividades profissionais. "Estar em formação implica um investimento pessoal, um trabalho livre e criativo sobre os percursos e os projetos próprios, com vista à construção de uma identidade, que é também uma identidade profissional" (NÓVOA, 1992, p. 13).

Quando se trata de formação de professores, não se refere apenas a à formação inicial, mas também à formação continuada, entendendo que os docentes não concluem seus estudos na licenciatura, mas devem seguir ampliando seus conhecimentos ao longo de sua carreira. Nesse sentido, Tardif defende que:

Tanto em suas bases teóricas quanto em suas consequências práticas, os conhecimentos profissionais são evolutivos e progressivos e necessitam, por conseguinte, de uma formação contínua e continuada. Os profissionais devem, assim, autoformar-se e reciclar-se através de diferentes meios, após seus estudos universitários iniciais. Desse ponto de vista, a formação profissional ocupa, em princípio, uma boa parte da carreira e os conhecimentos profissionais partilham com os conhecimentos científicos e técnicos a propriedade de serem revisáveis, criticáveis e passiveis de aperfeiçoamento (TARDIF, 2010, p. 249).

A formação continuada de professores deveria ser contínua, ou seja, estar em constante processo de (re)formação, buscando sempre a qualificação, por meio de novos aprendizados, visando 
melhorar a prática docente e o seu conhecimento profissional. Poderia ser definida como "um conjunto de ações de caráter processual, as quais devem acontecer dentro da escola e estar centradas nas necessidades dos professores e nos problemas vivenciados no cotidiano escolar" (TERRAZZAN; GAMA, 2007, p. 165). É realizada após a formação inicial, independente de estar ou não no exercício da profissão, como por exemplo, pós-graduação, cursos de extensão, a participação em eventos, tais como congressos, colóquios, seminários, entre outros.

Porém, não deveria ser vista apenas como um processo de atualização, ou de acumulação de certificados como um incentivo salarial ou promocional. Ela tem a função de melhorar 0 exercício da profissão, auxiliando a refletir sobre a prática docente determinando um processo constante de autoavaliação (IMBERNÓN, 2010). Assim, o docente deveria analisar criticamente o seu próprio desempenho e repensar, reorganizar o que já foi executado, para aperfeiçoar a sua atuação profissional.

\section{METODOLOGIA E ANÁLISE}

Por meio da pesquisa, foram analisadas as contribuições do PNAIC-Matemática para a formação continuada de professores alfabetizadores do município de São Borja.

Segundo a abordagem metodológica a pesquisa é qualitativa. Este é um método de investigação em que os dados não são quantificados e sim interpretados e analisados.

Para melhor compreensão do programa, foi realizada, inicialmente, uma análise dos documentos referentes ao PNAIC, fazendo um levantamento sobre os objetivos e a proposta do mesmo, bem como os motivos que levaram o governo federal a tomar essa iniciativa.

Os sujeitos participantes da pesquisa foram os professores alfabetizadores que participaram das formações oferecidas pelo PNAIC-Matemática no ano de 2014 e que, na época em que foi realizada a pesquisa, faziam parte do quadro de professores das escolas municipais de São Borja-RS. Na cidade, participaram das formações do PNAIC-Matemática, no ano de 2014, 89 professores alfabetizadores das 19 escolas da rede municipal de ensino que, na época, estavam atuando em turmas do $1^{0}$ ao $3^{0}$ ano do Ensino Fundamental. A formação contou com 1 coordenadora e 3 orientadoras de estudos. Os sujeitos da pesquisa foram todos do sexo feminino, portanto, ao se referir a eles, será utilizado o termo "professoras".

Para compreender as contribuições do PNAIC para a formação continuada de professores alfabetizadores, foi aplicado um questionário misto, composto por perguntas abertas e fechadas. Foram convidadas a participarem da pesquisa as 19 escolas da rede municipal de ensino da cidade de São Borja, que contavam com os anos iniciais do Ensino Fundamental. Porém, apenas 13 escolas concordaram em participar da pesquisa. Dessas, 10 eram da zona urbana e 3 da zona rural. No total, 24 professoras responderam ao questionário.

0 tempo de atuação das professoras variou entre 21 e 37 anos. A área de formação das professoras está apresentada no Gráfico 1. Das 24 professoras que participaram do estudo, 23 possuíam 0 curso normal e licenciatura/pedagogia. Apenas 1 delas possuía o curso normal como única habilitação para 0 ingresso no magistério. 
Gráfico 1 - Área de formação das professoras.

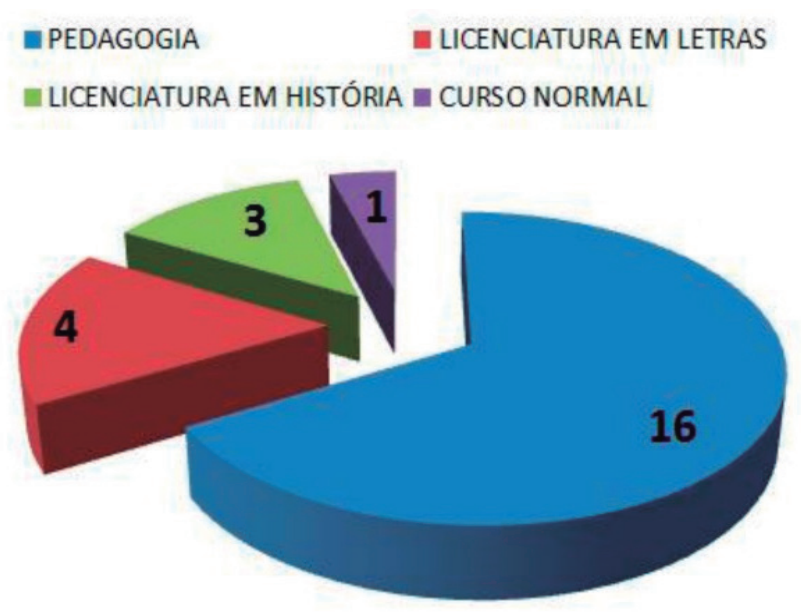

Fonte: Construção dos autores.

Das 24 professoras que responderam ao questionário, 1 i possuía pós-graduação em nível de Mestrado e 17 tinham especialização, conforme apresentado no Gráfico 2:

Gráfico 2 - Maior titulação dos sujeitos da pesquisa

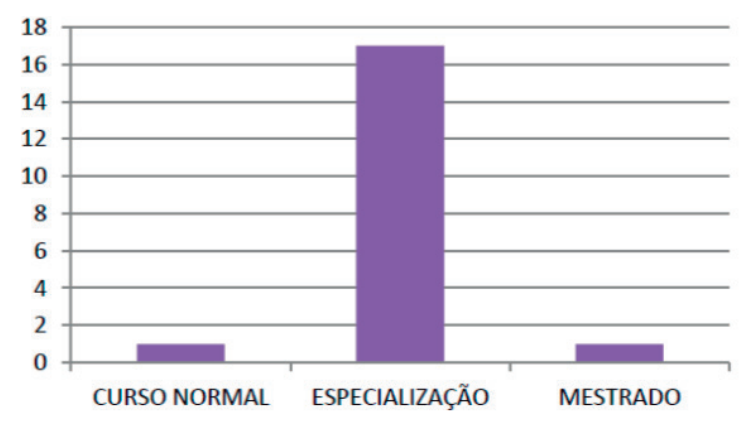

Fonte: Construção dos autores.

Para assegurar a confidencialidade dos dados, as professoras foram mencionadas neste trabaIho como P1, P2, ... P16.

A análise dos dados dos questionários foi realizada sob a luz da análise de conteúdo de Bardin (2011), fazendo uso do método de categorização. Esse método auxilia na interpretação dos dados, pois não introduz desvios no material, mas proporciona conhecer índices invisíveis, ao nível dos dados brutos (BARDIN, 2011).

A categorização é 0 agrupamento de elementos que apresentam características que os tornam semelhantes, por conter algo em comum, onde os dados brutos são transformados em dados organizados. É um processo importante para a área da pesquisa, para analisar os dados coletados, pois ajuda a esclarecer e interpretar esses dados. Segundo Bardin (2011, p. 147), categorização "é uma operação de classificação de elementos constitutivos de um conjunto por diferenciação e, em 
seguida, por reagrupamento segundo o gênero (analogia), com os critérios previamente definidos".

Os dados foram organizados em três categorias, a saber: Contribuições do PNAIC para 0 aprofundamento dos conteúdos, estratégias e recursos para ensinar Matemática, e o PNAIC e o planejamento das práticas.

A seguir, explicita-se cada uma dessas categorias.

\section{Categoria 1: Contribuições do PNAIC para 0 aprofundamento dos conteúdos.}

Esta categoria buscou identificar as contribuições para o aprofundamento dos conteúdos relacionado à Matemática, ensinados nos anos iniciais do Ensino Fundamental.

Na pergunta: "Sua participação no PNAIC Matemática levou você a adotar diferentes práticas em sala de aula? Comente", percebeu-se que as formações do PNAIC influenciaram as professoras a utilizar as metodologias apresentadas, pois a maioria passou a adotar diferentes estratégias de ensino. Dentre estas estratégias estão o uso de questões contextualizadas, jogos e materiais concretos, conforme o relato da professora P9.

"Modificou um pouco minhas práticas, pois passei a utilizar mais os materiais concretos (canudos, palitos, miniaturas) para a realização de atividades" (Professora P9).

Analisando a resposta da professora P9, infere-se que as formações influenciaram a sua prática docente, já que passou a utilizar materiais manipuláveis para o desenvolvimento das atividades em sala de aula, conforme foi sugerido nas formações do PNAIC-Matemática. Este tipo de iniciativa tem a capacidade de ser um agente de mudanças na prática docente, porém essa mudança não é imediata, mas um processo de constante aprendizado.

A professora P24 mencionou que após, as formações do PNAIC, passou a usar questões contextualizadas, considerando as realidades dos sujeitos do campo, já que atuava em uma escola localizada na zona rural.

"Sim, utilizando mais questões cotidianas, situações que comumente são vivenciadas nas famílias do campo" (Professora P24).

As formações consideraram a realidade daqueles que atuavam em escolas do campo, já que 0 cotidiano destes alunos não é o mesmo daqueles que vivem na cidade. Assim, contribuiu para que as professoras pudessem pensar em estratégias para trabalharem o conteúdo envolvendo Matemática utilizando elementos relacionados à realidade do campo. Abordar a Educação do Campo é também reconhecer a identidade dos sujeitos pertencentes a ela, dando possibilidades para que eles melhor compreendam a realidade em que estão inseridos.

Na pergunta "Os encontros do PNAIC contribuíram para melhorar a prática docente", a maioria respondeu que sim, justificando que o PNAIC trouxe uma metodologia prática e inovadora.

"Sim, o PNAIC traz uma metodologia prática, inovadora através do lúdico" (Professora P1).

Percebeu-se que as professoras apreciavam as sugestões de atividades práticas próximas à realidade do aluno e que poderiam ser trabalhadas de forma lúdica. Esta forma pedagógica de abordar os conteúdos matemáticos foi incentivada nas formações e está explicitada no caderno de apresentação do PNAIC-Matemática afirmando que: 
Não há necessidade de atividades sofisticadas e que demandem um excessivo tempo do professor para seu planejamento e execução. Atividades simples possuem grande potencial pedagógico desde que contribuam para aproximar situações do cotidiano a situações da sala de aula (BRASIL, 2014a, p. 25).

Ou seja, é possível criar situações em que 0 aluno utilize os conceitos matemáticos na resolução de um problema, sem a necessidade de muitos materiais didáticos. As formações levaram sugestões de atividades dessa natureza, considerando a realidade em que as professoras atuavam.

Mesmo após a participação da formação do PNAIC/Matemática, metade das professoras respondeu que ainda tinham dificuldades para ensinar Matemática e afirmaram que o seu maior problema estava no ensino da divisão, do raciocínio lógico, interpretação e da organização estatística.

As professoras P3 e P23 mencionaram suas dificuldades em trabalharem a organização estatística, conteúdo que foi desenvolvido nas formações do PNAIC:

"No pré e $1^{0}$ ano considero que a organização estatística de registro exige muita criatividade para levar o educando a compreensão e assimilação destes conhecimentos" (professora P3).

"Estatística (representação gráfica). As crianças necessitam de uma compreensão do registro e outros conceitos (quantificação, grandezas)" (professora P23).

A dificuldade em trabalhar com 0 aluno 0 conteúdo de organização estatística foi citada por várias professoras. Porém, nas formações, houve o momento em que este tema foi abordado. 0 PNAIC apresentou várias sugestões de atividades para serem trabalhadas em sala de aula sobre esse tema.

Elas também relataram que possuíam dificuldades para ensinar Geometria, o que foi amenizado após as formações do PNAIC.

Segundo a professora P23, ela percebeu que a Matemática não trata apenas de números e operações, revelando que, antes das formações, as questões trabalhadas em sala de aula envolvendo a Matemática não eram contextualizadas.

"O PNAIC ofereceu suplemento para a reformulação de conhecimento sobre a Matemática nos anos iniciais, esta é muito mais que números e operações, são formas e grandezas, são dados e exploro atualmente com atividades lúdica e oportunizando a vivência de fatos que utilizem a matemática no seu dia a dia" (Professora P3).

Ao mencionar a palavra "formas", observa-se que a professora refere-se à Geometria, que foi um tema abordado nas formações e apresentou sugestões para 0 trabalho em sala de aula. Após a sua participação nas formações do PNAIC, ela percebeu que a Geometria poderia ser trabalhada nesta etapa de escolarização. Segundo os PCN,

a Geometria é um campo fértil para se trabalhar com situações-problema e é um tema pelo qual os alunos costumam se interessar naturalmente. 0 trabalho com noções geométricas contribui para a aprendizagem de números e medidas, pois estimula a criança a observar, perceber semelhanças e diferenças, identificar regularidades e vice-versa (BRASIL, 1997, p. 39). 
Dessa forma, reconhece-se a importância desse conceito no desenvolvimento do aluno, pois estimula a "conjecturar, experimentar, registrar, argumentar e comunicar procedimentos e resultados" (BRASIL, 2014b, p. 14), além de auxiliar o aluno a compreender o mundo em que vive estabelecendo relações entre os conceitos presentes no seu dia a dia de forma organizada.

\section{Categoria 2: Estratégias e recursos para ensinar Matemática.}

Esta categoria buscou compreender como as formações do PNAIC contribuíram para que as professoras utilizassem estratégias e recursos para ensinar Matemática.

Além de questões envolvendo 0 ensino-aprendizagem relacionado à Matemática, as professoras relataram problemas relacionados ao desenvolvimento dos alunos, como é possível perceber nos relatos a seguir.

"Sim, ainda há bastante dificuldade devido a interpretação e a falta de raciocínio, o pensar, 0 concentrar e a atenção são habilidades que não estão bem desenvolvidas" (professora P8).

"Resolução de problemas, pois os alunos não querem raciocinar" (professora P20).

"Ainda tenho dificuldades. A interpretação de 'situações-problema' é uma delas" (professora P24). ${ }^{5}$

Várias professoras citaram que se incomodavam com a falta de atenção, concentração e interpretação de seus alunos, demonstrando, assim, que esperavam que eles apresentassem um comportamento 0 qual ainda não estavam prontos para demonstrar. No caderno de apresentação do PNAIC-Matemática, encontra-se a seguinte afirmação:

Embora pareça evidente, devemos nos lembrar que crianças pensam como crianças. [...] Além disso, nunca podemos esquecer que a criança ficará na escola por muitos anos, por isso não precisamos ter pressa para forçar algumas atitudes que, muitos estudos indicam, somente serão plenamente dominadas mais tarde (BRASIL, 2015, p. 19).

Dessa forma, é importante refletir que os alunos, que as professoras mencionam, têm entre seis e oito anos de idade e ainda apresentam como característica a agitação. É nessa etapa que serão desenvolvidas pelos alunos as habilidades citadas pelas professoras, sendo a Matemática uma ferramenta importante para auxiliar nesse desenvolvimento.

Foram listados nove recursos didáticos e manipuláveis e as professoras deveriam responder quais eram mais utilizados em sala de aula. As respostas obtidas por meio deste questionamento originaram o gráfico seguinte. 
Gráfico 3 - Atividades utilizadas nas aulas de Matemática.

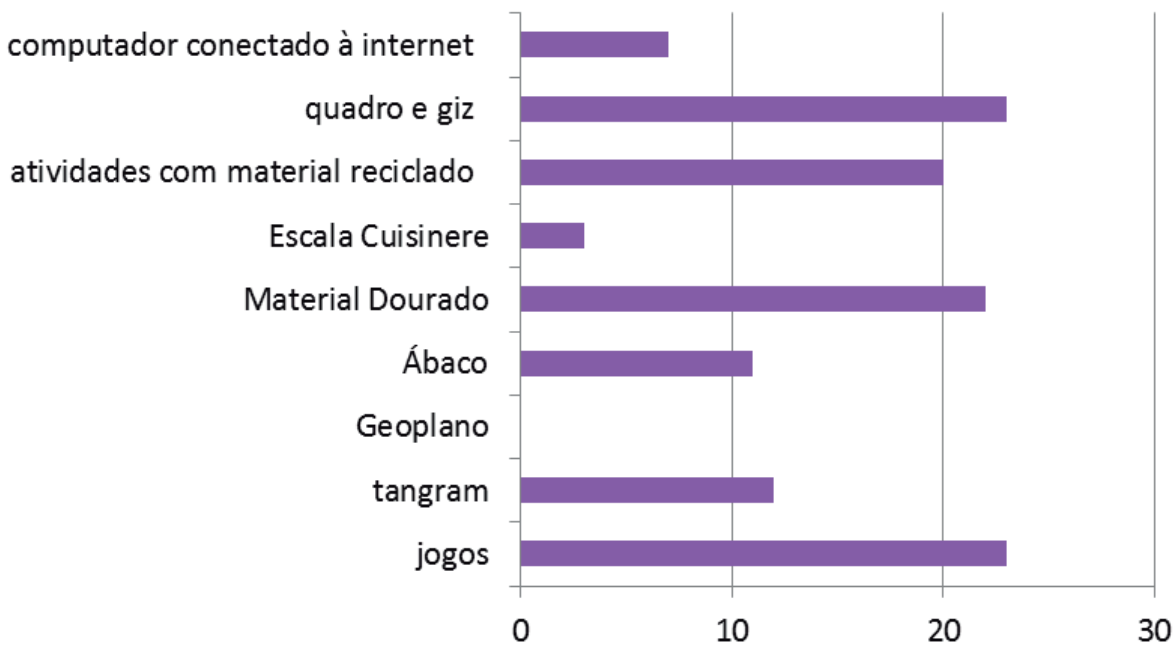

Fonte: Construção dos autores.

Segundo o Gráfico 3, a maioria dos docentes utilizava o jogo e atividades com material manipulável, evidenciando uma tendência de valorizar o aspecto lúdico durante as aulas de Matemática.

0 jogo é uma metodologia que é incentivada a ser utilizada pelos professores por favorecer 0 desenvolvimento dos alunos em diversos aspectos. Nesse sentido, Smole menciona que:

0 trabalho com jogos nas aulas de Matemática, quando bem planejado e orientado, auxilia o desenvolvimento de habilidades como observação, análise, levantamento de hipótese, busca de suposições, reflexão, tomada de decisão, argumentação e organização, que estão estritamente relacionadas ao chamado raciocínio lógico (SMOLE, 2007, p. 09).

Assim, 0 aluno é estimulado pelo caráter desafiador do jogo, que conforme Grando:

É fundamental inserir as crianças em atividades que permitam um caminho que vai da imaginação à abstração, através de processos de levantamento de hipóteses e testagem de conjecturas, reflexão, análise, síntese e criação, pela criança, de estratégias diversificadas de resolução dos problemas em jogo. 0 processo de criação está diretamente relacionado à imaginação (GRAND0, 2000, p. 20).

0 uso do jogo não deve ser irrestrito: uma reflexão sobre a sua finalidade é essencial. "Eles podem vir no início de um novo conteúdo com a finalidade de despertar o interesse da criança ou no final com o intuito de fixar a aprendizagem e reforçar o desenvolvimento de habilidades" (FIORENTINI, MIORIM, 1990, p. 5). Dessa maneira, cabe ao professor avaliar sobre o seu uso e qual o momento adequado para utilizá-lo.

Ao serem questionadas quanto aos maiores desafios para ensinar Matemática, aparecem algumas respostas que merecem atenção: levar o aluno a compreender conceitos com materiais concretos e passar para 0 abstrato. 
Das 24 professoras que responderam o questionário, 6 encararam como um desafio 0 uso de materiais manipuláveis para trabalhar algum conceito matemático, fazer seus alunos passar do concreto para 0 abstrato, conforme menciomou a professora P4:

"É conseguir sair do concreto para o simbólico com todos os educandos ou a maioria, entendendo o processo lógico matemático com facilidade" (professora P4).

"0 aluno desapegar-se do concreto e desenvolver o raciocínio (pensamento) abstrato" (professora P9).

"Meus maiores desafios estão em conseguir que as crianças consigam transpor o que é ensinado com material concreto para 0 abstrato" (professora P1).

Segundo Nacarato (2005), para o professor, o material manipulável tem relação com o conceito que está sendo trabalhado. Porém, não há nenhuma garantia que os alunos vejam as mesmas relações nos materiais que vemos. Assim, ela afirma que:

[...] o papel do formador de professores seja de trazer essas questões para reflexão, problematizando o uso de materiais didáticos nas aulas de Matemática e discutindo alguns significados do que seja, trabalhar no concreto com alunos da Educação Básica, em qualquer um de seus níveis (NACARAT0, 2005, p. 6).

Jogos e materiais concretos são importantes instrumentos para os professores dos anos iniciais trabalharem conceitos matemáticos necessários nessa etapa de escolarização, pois, permite ao professor relacionar conceitos teóricos com práticos e, assim, promover em seus alunos a aprendizagem e o desenvolvimento do raciocínio lógico, bem como auxiliá-los a compreender conceitos relacionados a essa ciência. Porém, o professor necessita de subsídios para desenvolver atividades de forma responsável que auxiliem o aluno a construir o seu próprio conhecimento.

Tornar a aula prazerosa é uma estratégia eficiente, porém, é necessário refletir se está adequada aos objetivos do conteúdo a ser trabalhado. Além disso, é importante observar que não há, necessariamente, uma correspondência unívoca entre uma aula prazerosa e aprendizado, já que uma aula tradicional também tem o potencial para fazer os educandos aprenderem.

\section{Categoria 3: 0 PNAIC e o Planejamento das Práticas}

Esta categoria investigou como o PNAIC influenciou as professoras no planejamento das práticas em sala de aula.

Ao serem questionadas sobre o que as motivou a participar do PNAIC de Matemática no ano de 2014, as professoras responderam que se sentiram motivadas pelo trabalho desenvolvido no ano anterior com o PNAIC-2013, em que a ênfase foi em leitura e escrita.

"A participação do PNAIC Língua Portuguesa e os bons resultados que obtive com minha turma" (professora P1). 
Ao perceber que as metodologias e as formações proporcionaram conhecimentos que melhoraram a prática em sala de aula e, consequentemente, 0 aprendizado do aluno, não apenas motivou como também estimulou as professoras a aceitar as propostas e colocá-las em prática, desenvolvendo confiança nas formações e nas metodologias apresentadas. Nesse sentido, Imbernón afirma que:

Somente quando os professores constatam que o novo programa formativo ou as possíveis mudanças que a prática oferece repercutirão na aprendizagem de seus alunos, mudarão suas crenças e atitudes de maneira significativa, supondo um benefício para os estudantes e para a atividade docente. É quando a formação será vista como um benefício individual e coletivo, e não como uma "agressão" externa ou uma atividade supérflua (IMBERNÓN, 2010, p. 32).

As formações têm que considerar que as professoras participarão se perceberem em suas turmas resultados efetivos. Além disso, elas não dispõem de tempo para participar de atividades formativas que contribuam pouco à prática docente.

Em diversas questões, as professoras alegaram como motivação para participar das formações do PNAIC-Matemática a busca por novos conhecimentos. Acredita-se que são profissionais que se preocupam com a aprendizagem dos alunos, já que, para elas, quanto mais conhecimentos adquirirem, melhor será o seu desempenho em sala de aula. Para Nóvoa, "0 trabalho do professor consiste na construção de práticas docentes que conduzam os alunos à aprendizagem" (2009, p. 30). É por meio da formação continuada que será possível encontrar os conhecimentos necessários para aprimorar a prática docente.

No depoimento a seguir nota-se que a busca por novos conhecimentos é um fator que motivou a participação das professoras em cursos de formação.

"Naquele momento, fomos convidadas a participar do PNAIC, e o que me incentivou foi buscar novos conhecimentos para aperfeiçoar a metodologia de como mediar o ensino-aprendizagem na disciplina, linguagem de Matemática" (professora P3).

"Além de ser um projeto do governo, achei muito interessante para diversificar as atividades propostas aos alunos e vislumbrar novas estratégias pedagógicas para que eles consolidem conhecimentos" (professora P18).

Observou-se que nem todas as participantes da formação estavam motivadas pela mesma razão para a vivência do processo. Havia aquelas que se sentiram motivadas pela busca por novos conhecimentos, outras por novas metodologias que poderiam auxiliar seus alunos no processo de aprendizagem. Por isso, é importante refletir sobre os anseios e angústias desses profissionais e oferecer formações que ajudem na solução de problemas que surgem no dia a dia dos docentes. Isso é o que Terrazzan e Gama também defendem:

Assim sendo, consideramos fundamental que as instituições, que hoje vêm investindo no desenvolvimento profissional dos professores, tomem como referência e ponto de partida para a elaboração de suas propostas de formação continuada, a análise das necessidades formativas desses profissionais (TERRAZZAN; GAMA, 2007, p. 168). 
A formação continuada deve ser centrada em problemas práticos e corriqueiros de uma escola e que ajude os profissionais desta área a criar alternativas de mudanças no contexto em que se produz a educação (IMBERNÓN, 2010). Oferecer formações que não levam em conta as necessidades de uma escola não contribuem para melhorar a educação.

Ao serem questionadas quanto às expectativas em relação ao PNAIC, várias professoras relataram que esperavam do curso atividades práticas para desenvolver em sala de aula.

"As minhas expectativas seriam as anteriores, novas estratégias, trocas de ideias com os demais colegas, enfim novos caminhos para que os educandos atinjam, e se aprimorem do conhecimento" (professora P18).

"Muito boa, tendo em vista que as edições anteriores foram muito interessantes, pelas trocas ocorridas entre os participantes" (professora P2).

"Eram muitas, pois o programa se apresentava como uma nova perspectiva para 0 ensino de Matemática. E, em alguns aspectos foi assim" (professora P1).

"Entre tantas expectativas, a mais importante era auxiliar os alunos a raciocinarem, compreenderem a matemática de forma lúdica e simples, sem decoreba" (professora P21).

Analisando a escrita das professoras, é possível perceber que elas esperavam que as formações auxiliassem a desenvolver as suas atividades em sala de aula, além do fato de muitas citarem que apreciaram a troca de experiências com os colegas. Essas informações vêm ao encontro com 0 que afirma Terrazzan e Gama (2007):

Percebe-se, então, que os professores motivam-se basicamente por uma formação que possa contribuir para a melhoria do seu trabalho em sala de aula e para 0 enfrentamento dos problemas vivenciados no ambiente escolar. Lembrando que eles também consideram muito importante uma formação que privilegie a troca de experiências com os colegas, da associação destas três motivações podemos ter uma indicação de que os professores sentem a necessidade de ações coletivas no trabalho escolar (TERRAZZAN; GAMA, 2007, p. 180).

Ou seja, o que motiva essas professoras são formações baseadas na realidade a qual elas trabalham, considerando as situações diárias que ocorrem na escola, já que as "situações que os professores são obrigados a enfrentar (e a resolver) apresentam características únicas, exigindo, portanto, respostas únicas" (NÓVOA, 1992, p. 16). Além disso, elas querem conhecer metodologias que as auxiliem no processo de ensino e aprendizagem de seus alunos.

Já a professora P18 afirmou que os encontros proporcionaram o repensar da sua prática docente.

"Sim, porque muitas estratégias que usávamos caíram no esquecimento e esses encontros vieram para fazermos uma análise da nossa prática”. (Professora P18) 
Ela mencionou que os encontros do PNAIC-Matemática a motivaram a refletir sobre sua atuação como docente. Neste sentido, entende-se que a formação continuada deve promover 0 crescimento profissional por meio da reflexão, conforme explicita Nóvoa:

A formação não se constrói por acumulação (de cursos, de conhecimentos ou de técnicas), mas sim através de um trabalho de reflexividade crítica sobre as práticas e de (re)construção permanente de uma identidade pessoal. Por isso é tão importante investir a pessoa e dar um estatuto ao saber da experiência (NÓVOA, 1992, p. 13).

Apenas participar de um curso de formação continuada não significa que haverá um crescimento profissional, mas o fato de analisar de forma crítica a sua atuação em sala de aula permite repensá-la e reconstruí-la. Nesse sentido, acredita-se que é essencial oferecer formação continuada de forma contínua, pois é por meio dela que o professor terá a oportunidade de repensar a sua prática, bem como aprimorar o seu conhecimento.

Quanto às mudanças mais significativas destaca-se que as formações levaram as professoras a repensar a sua prática, utilizando novas metodologias, fazendo uso de materiais concretos para desenvolver atividades envolvendo cálculos, além de que passaram a utilizar questões contextualizadas.

"Acredito que a mudança está na mudança de metodologia ou em sua renovação. Pois, este projeto foi uma injeção de ânimo para quem está há muito tempo em sala e precisa e quer mudar em prol de uma aprendizagem mais efetiva e atraente para seus alunos" (professora P2).

Pela fala da professora P2, observa-se que ela esperava por uma formação continuada pensada na realidade do cotidiano escolar, promovendo, desse modo, uma mudança em sua prática pedagógica e não uma formação generalista que não considera as necessidades formativas dos docentes. Por isso, ela estava motivada e disposta a realizar as atividades apresentadas, para, assim, experimentar as novas propostas e refletir sobre elas. "Os indivíduos que se integram nesse processo descobrem novos horizontes, novas maneiras de ser professor" (FOSTER; LEITE, 2014, p. 882). Ou seja, estão abertos a novas ideias, dispostos a repensar suas práticas e experimentar as metodologias sugeridas.

Há um destaque para o fato de a grande maioria citou a troca de experiência entre os colegas, demonstrando que eles valorizam esses momentos e reconhecem que os auxiliam na melhoria da prática docente.

"A troca de experiências entre colegas" (Professora P8).

"A troca de experiências renova e proporciona conhecimentos que contribui para a prática docente" (Professora P23).

"A troca de experiências [...] é muito enriquecedor para qualquer professor" (Professora P15).

A troca de experiência entre professores é o momento em que eles compartilham suas angústias, dúvidas e inseguranças, além de discutir sobre novas formas de ensinar, assim como compartilhar metodologias e materiais didáticos. É um espaço importante para o crescimento profissional e que não pode ser negado. 
As formações são importantes não apenas para levar aos professores novas metodologias, mas, também, para proporcionar momentos de reflexão e repensar a prática docente em sala de aula por meio da troca de experiência entre eles. A docência é um trabalho solitário, onde o docente realiza suas tarefas cotidianas dentro de uma sala de aula com pouca interação com os colegas, sem a oportunidade de aprender e refletir por intermédio da sua própria prática e da prática de seus colegas de profissão.

A criação de espaços para discutir e avaliar as situações-problema que acontecem em sala de aula auxilia o desenvolvimento da escola e também do professor (IMBERNÓN, 2010), já que "propostas teóricas só fazem sentido se forem construídas dentro da profissão, se forem apropriadas a partir de uma reflexão dos professores sobre o seu próprio trabalho" (NÓVOA, 2009, p. 19). É no seu dia a dia que o professor aprende e também aperfeiçoa seus conhecimentos, por meio de vivências que só acontecem nesse ambiente.

Por isso, é importante ouvi-los, para, assim, conhecer a sua trajetória pessoal e profissional considerando suas angústias e dificuldades encontradas na profissão. Portanto, é necessário investir na formação dos professores, pois é através deles que as mudanças na educação serão possíveis, já que a educação não pode mudar se os professores não mudarem, pois são eles os executores das propostas educativas (IMBERNÓN, 2010). É no ambiente escolar que o docente vivencia situações que provocam reflexões e auxiliam na tomada de decisões, as quais serão aprimoradas ao longo da sua carreira.

\section{CONSIDERAÇÕES FINAIS}

Por meio dessa pesquisa e das reflexões em torno dos dados obtidos, percebeu-se que 0 PNAIC-Matemática trouxe várias contribuições às professoras alfabetizadoras do município de São Borja/RS que participaram desta iniciativa. Dentre elas, destacam-se as metodologias que foram trabalhadas nas formações e auxiliaram as docentes no processo de ensino e aprendizagem. Além do mais, proporcionou muitas reflexões em torno da atuação delas em sala de aula, promovendo 0 repensar da prática pedagógica.

Ao refletir quanto ao que as professoras esperavam de um curso de formação continuada, percebe-se que elas valorizavam as metodologias e conhecimentos que tenham o potencial para melhorar a prática em sala de aula e também auxiliá-las a resolver situações-problema próprias desse ambiente de forma eficiente. Para que isso aconteça é indispensável oferecer uma formação que considere a realidade na qual elas trabalham.

As professoras alegaram que as metodologias apresentadas no PNAIC-Matemática eram práticas, baseadas na realidade a qual elas trabalhavam. Isso também foi uma característica citada por várias professoras nas respostas aos questionários e que elas gostaram bastante. Percebe-se que as formações apresentaram várias estratégias para trabalhar os conteúdos matemáticos em sala de aula, com jogos e materiais manipuláveis, por exemplo. Por isso, é importante levar aos professores diferentes formas de desenvolver o seu fazer pedagógico, a fim de oportunizar aos educandos a interação com o conhecimento através de várias metodologias pelas quais eles possam aprender.

Mesmo as professoras afirmando que conheciam as metodologias, com o passar dos anos e no corre-corre do dia a dia, acabaram deixando de utilizá-las. Por meio do PNAIC, sentiram-se motivadas a colocar em prática esses conhecimentos novamente. Nesse sentido, ao comparar as metodologias, tiveram a oportunidade de repensar e avaliar a sua atuação.

Quando as professoras foram questionadas sobre as contribuições do PNAIC, relataram que, após as formações, compreenderam a importância da Alfabetização Matemática nos anos iniciais 
do Ensino Fundamental. Isso demonstra que essa iniciativa proporcionou uma nova perspectiva em relação à Matemática, levando as alfabetizadoras a valorizar atividades relacionadas a esse assunto. Por meio das respostas das docentes, nota-se que antes da participação no PNAIC, para o planejamento das aulas, baseavam-se em livros didáticos com atividades que não faziam parte da realidade do aluno, além de exercícios com cálculos exatos.

Um dos pontos citados entre a maioria das professoras como o que mais agradou nas formações foi a troca de experiência entre os colegas. Assim, percebe-se que momentos como este são pouco comuns nessa área, apesar da influência positiva que exerce no desenvolvimento e melhoria da profissão. Por isso, é importante oferecer espaços de reflexão que valorizem os saberes que eles possuem e, assim, desenvolver as suas práticas baseadas na realidade a qual eles estão inseridos.

As formações do PNAIC-Matemática desenvolveram muitas atividades envolvendo material concreto, porém, as professoras apresentaram dúvidas nesse sentido, pois tinham dificuldades de fazer seus alunos passar do concreto para 0 abstrato ao utilizar essas atividades. Também relatam que ainda se sentiam inseguras para ensinar alguns conceitos envolvendo a Matemática, como, por exemplo: divisão, estatística e Geometria.

A formação continuada deveria ser oferecida de forma contínua, já que um professor encontra-se sempre em processo de formação e em constante aprendizado. Acredita-se que o PNAIC foi uma excelente iniciativa do governo federal, que ofereceu uma oportunidade para os professores adquirirem novos aprendizados, aperfeiçoar e refletir sobre a prática docente.

Conclui-se que o problema da dificuldade dos alunos em aprender Matemática não está apenas no professor, nas suas crenças, ou, ainda, na formação inicial deficiente ou "fraca". As políticas educativas também precisam oferecer aos docentes formações que considerem suas angústias e dificuldades, adequadas ao cotidiano escolar o qual estão inseridos e que os levem a refletir sobre a sua atuação nesse ambiente. Além disso, é necessário oferecer escolas com infraestrutura adequada para os professores desenvolverem o seu trabalho com eficiência. Cabe ressaltar que a melhoria da prática docente é resultado do compromisso de cada professor com seu próprio desenvolvimento pessoal e profissional.

\section{REFERÊNCIAS}

BARDIN, L. Análise de conteúdo. São Paulo: Edições 70, 2011.

BRASIL. 0 Ministro de Estado da Educação. Portaria No 867, de 4 de Julho de 2012. Institui o Pacto Nacional pela Alfabetização na Idade Certa e as ações do Pacto e define suas diretrizes gerais. Brasília: MEE, 2012.

. Ministério da Educação. Resolução/CD/FNDE nº 4, de 27 de fevereiro de 2013. Estabelece orientações e diretrizes para o pagamento de bolsas de estudo e pesquisa para a Formação Continuada de Professores Alfabetizadores, no âmbito do Pacto Nacional pela Alfabetização na Idade Certa. Brasília: FNDE, 2013. Disponível em: https://bit.ly/3g5uhJG. Acesso em: 24 jul. 2018.

Pacto Nacional pela Alfabetização na Idade Certa - Apresentação Alfabetização Matemática. Brasília, MEC/SEB, 2014a. 72 p. 
Pacto Nacional pela Alfabetização na Idade Certa - Caderno 5 Geometria. Brasília, MEC/SEB, 2014b. 96 p.

Pacto Nacional pela Alfabetização na Idade Certa. Interdisciplinaridade no ciclo de alfabetização. Caderno de Apresentação / Ministério da Educação, Secretaria de Educação Básica, Diretoria de Apoio à Gestão Educacional. Brasília: MEC, SEB, 2015.

MEC. Secretaria de Educação Básica. Diretoria de Apoio à Gestão Educacional. Pacto Nacional Pela Alfabetização Na Idade Certa. Documento Orientador. Brasília: MEC, 2017. Disponível em: https://bit.ly/2EidFQM. Acesso em: 24 abr. 2018.

. Secretaria de Educação Fundamental. Parâmetros curriculares nacionais: Matemática /Secretaria de Educação Fundamental. Brasília: MEC /SEF, 1997.

CANDAU, V. Formação continuada de professores/as: questões e buscas atuais. Rio de Janeiro: Revista Novamerica on-line. Edição n ${ }^{0}$ 122. Rio de Janeiro: NOVAMERICA, 2009. Disponível em: https://bit.ly/2POGHqd. Acesso em: 17 abr. 2018.

FIORENTINI, D.; MIORIM, M. A. Uma reflexão sobre o uso de materiais concretos e jogos no ensino de Matemática. Boletim da Sociedade Brasileira de Educação Matemática. São Paulo: SBEM-SP, n. 7, p. 1-3, 1990.

FORSTER; LEITE. Formação continuada de professores: da parceria entre universidade e escola ao protagonismo e reconhecimento do trabalho docente. Revista Diálogo Educacional, v. 14, n. 43, p. 865-887, 2014.

GARCIA, C. M. Formação de Professores. "Para uma mudança educativa.” Portugal: Porto Editora, 1999.

GRANDO, R. C. 0 conhecimento matemático e 0 uso de jogos na sala de aula. 2000. 239 f. Tese (Educação) - Universidade Estadual de Campinas. Campinas, 2000.

IMBERNÓN, F. Formação continuada de professores. Porto Alegre: Artmed Editora, 2010.

NACARATO, A. M. "Eu trabalho primeiro no concreto." Revista da Educação Matemática. Vol 9, No. 9-10, p.1-6, 2005

NÓVOA, A. Formação de professores e profissão docente. In: (Org.). Os professores e sua formação. Lisboa,: Publicações Dom Quixote, 1992.

Professores: Imagens do futuro presente. Lisboa: EDUCA, 2009. Disponível em: https://bit.ly/32XaHLM. Acesso em: 13 mar.18 2018.

SMOLE, K. S.; DINIZ, M. I.; MILANI, E. Cadernos do Mathema: Ensino Fundamental: Jogos de Matemática de $\mathbf{6}^{0}$ a $\mathbf{9}^{0}$ ano, V. 2, Porto Alegre: Artmed Editora, 2007.

TARDIF, M. Saberes docentes e formação profissional. Petrópolis: Editora Vozes, 2010.

TOJA, A. P. U. As contribuições do PNAIC-Matemática na formação de professores alfabetizadores do município de São Borja. (2018). 96 p. Dissertação (Mestrado em Educação Matemática) - Universidade Federal de Santa Maria, Santa Maria, 2018. 
UNIVERSIDADE FEDERAL DE PELOTAS. Pacto Nacional pela Alfabetização na Idade Certa (PNAIC). Pelotas, 2018. Disponível em: http://pnaic.ufpel.edu.br/. Acesso em: 19 jun. 2018.

UNIVERSIDADE FEDERAL DE SANTA MARIA. Pacto Nacional pela Alfabetização na Idade Certa (PNAIC). Santa Maria, 2018. Disponível em: http://coral.ufsm.br/pactonacional/index.php/sobre. Acesso em: 19 jun. 2018.

RECEBIDO EM: 28 ago. 2019

CONCLUÍDO EM: 27 fev. 2019 